\title{
Is it enough to put yourself in another's shoes? Thoughts about the relationship between empathy and prosocial behavior
}

\author{
Eleonora Pizzi \\ Degree in Clinical and Community Psychology, European University of Rome, Italy
}

\begin{abstract}
Empathy is the ability to understand another one's mental states in terms of emotions and thoughts. In the common thought, often, this skill is directly related to the ability to act in a prosocial, or moral, way. Clinical literature shows us that some neural deficits and psychological disorders can actually cause a significant lack of empathic ability and therefore the implementation of socially maladaptive behaviors, even criminal. However, there are also some diagnostic categories characterized by failure to "put yourself in another's shoes", but patients do not usually act in an antisocial way; then, not all the criminals meet the criteria for psychiatric diagnosis. So, the question is: only low levels of empathy lead to antisocial behaviors? And if so, does therapeutic interventions for empathic skill entail moral enhancement? The present work aims to answer to all those issues through a multilevel and cross-disciplinary analysis of psychology, neurosciences and philosophy literature.
\end{abstract}

\section{RIASSUNTO}

L'empatia è definita come la capacità di comprendere i processi psichici altrui in termine di emozioni e pensieri. Spesso, nel pensiero comune, si è portati a pensare che esista un rapporto direttamente proporzionale tra questa abilità e il mettere in atto comportamenti prosociali o morali. La letteratura clinica ci mostra come alcuni deficit a livello neurale o alcuni disturbi psicologici possano effettivamente comportare una significativa perdita della capacità empatica e di conseguenza la messa in atto di comportamenti socialmente disadattivi. Allo stesso tempo, però, esistono categorie diagnostiche caratterizzate da l'incapacità di "mettersi nei panni altrui"; inoltre non tutti i criminali soddisfano i criteri per poter ricevere una qualunque diagnosi psichiatrica. E quindi, il punto centrale è: i comportamenti antisociali sono dovuti solo a bassi livelli di empatia? E se così fosse, gli interventi terapeutici volti a migliorare le capacità empatiche comportano anche maggiori capacità di condotta morale? Tale lavoro ha come obiettivo quello di rispondere a tali quesiti tramite un'analisi multidisciplinare e su più livelli della letteratura psicologica, neuroscientifica e filosofica.

\section{RESUMEN}

La empatía es la habilidad para entender el estado mental de otras personas en términos de emociones y pensamientos. Para la opinión pública, esta habilidad se relaciona frecuentemente con la capacidad de actuar en una manera moral o en favor de la sociedad. La literatura clínica nos muestra que algunas deficiencias neuronales y desordenes psicológicos pueden causar una falta significativa de empatía, llegando a generar comportamientos socialmente inadaptados e incluso criminales. Por otro lado, existen también algunos diagnósticos en los cuales se aprecia una incapacidad de "ponerse en los zapatos ajenos" y sin embargo estos pacientes no actúan en una manera antisocial; por tanto, no todos los criminales cumplen con los criterios de un diagnóstico psiquiátrico. Entonces la pregunta es: ¿solamente los bajos niveles de empatía son suficientes para generar comportamientos antisociales? Y en ese caso, ¿las intervenciones terapéuticas para aumentar la empatía conllevan un crecimiento moral? El presente trabajo busca responder todos estos interrogantes a través de un análisis multinivel e interdisciplinario de la literatura psicológica, neurocientífica y filosófica.

\section{Introduction}

In 1961, fifteen years after the Nuremberg Trials, the Nazi regime was in the spotlight and on trial again in Jerusalem represented by Adolf Eichmann, who bears the main responsibility for the deportation and extermination of Czechoslovak Jews.

Among all the journalists went to Israel to document this trial, philosopher Hannah Arendt shocked the international audience because of her Eichmann's description not as a bloody monster, a not-able-to-live-in-society fellow or a brilliant criminal-minded, but as a simple dutiful pen-pusher.

Indeed, Eichmann defended himself declaring "I just followed orders"; Neither hate nor regret in his words, only a mere claim. According to the very-well know book arisen from Arendt's witness, the Nazi officer appeared as a dull and grim employee who blindly obeyed the instruction. He was, therefore, the ultimate incarnation of "the banality of evil".

Eichmann's personal defense caused a strong overreaction within humanities sciences, which leaded research aiming to the knowledge of moral action phenomenology.

The long-standing issue about what can be considered moral could seem an Ethics' prerogative but, therefore, is from moral phenomenology studies that this philosophy branch arose: from Plato's four cardinals virtues and Aristotelian "Nichomachean Etichs", to the concept of obedience to the Natural Law expressed by Thomas Aquinas and William of Ockham, until the modern trend, as the German philosophical-ethics school, of which Kant is the leading figure.

Otherwise, the definition of what morality is, can be transposed into Psychology through the operationalization and the transformation of the term into the construct "pro-social behavior" 
defined as "a set of voluntary behaviors aim to enhance others' wellbeing".

Inside literature there is an overall agreement on how pro-social behavior can't be reduce to a global and widespread construct, but it must be seen as a motivational force based on several and different psychological mechanism as: guilt, expectation of mutual benefit, self-well-being, etc. It must be also underline how those "calls to action" can't be studied as static features, because of their evolution trough the developmental stages.

Of all those motivational forces that are the basis of moral or prosocial behaviors, the following work is going to treat empathic ability in order to answer to a very specific question: could it be possible that unmoral actions are caused by a total lack of empathy?

\section{On the problem of empathy}

Psychology is interested in studying empathy since the beginning: Edward Titchner, founder of American Functionalism, was the first to introduce the translation of merely philosophical term "Einfühlung" ("feeling into") in Empathy, defined as "the process of humanize objects by feeling ourselves into them".

The Psychoanalytic movement, for which mental development is grounded in interpersonal relationships, took an interest in Titchner's definition: according to Freud empathy is another one's inner reality intuition located in the pre-conscious level that could be bring into consciousness only by relationship. Because of its characterization, empathy can be analyzed not only as a complex mental activity constituent element, but also as integral part of therapeutic setting.

It's important to remember that immediately after Freud's death, and also during his last years, inside Psychoanalysis has been developed an actual schism; firstly, with Jung and his conceptualization of "Collective Unconscious", then Erickson's sociocultural theory and then Mahler's, Anna Freud's and Winnicott's developmental stages studies.

Of all of those post-Freudian tendencies, Self-Psychology leaded by Heinz Kohut, is the principal one focused on the study of empathy, during the 1970's, declaring that our empathic experiences are useful tools for self-construction. According to Kohut, infants develop their self through experiences, especially through parental relationships: positive or negative self-image is developed by the way we are perceived by others and how we internalized this image: "If parents experienced a strong self-confidence in their child, they will show agreement to son's prideful exhibit of his flourishing self. Does not matter how hardly reality hits infant's grandiosity, being approved from parents will keep alive part of initial felling of grandeur, which is the core of self-esteem and self-safety care".

And so, empathy plays a vital role during therapeutic relationship: a participating but also detached enough analysis helps therapist in understanding and communication processes with patient, helping transfert, too. Therefore, the therapist could give to patient a picture of reality that he could immediately catch because it represents the echo of living and feelings.

If according to Psychoanalysis empathy is a truly interesting and also important object of study, because is an essential tool for catch other's inner reality, for the same reasons is a taboo inside Behaviorism movement. Watson argued that empathy could not be countable because is a product of the mind, which in turn is not directly observable; so, this psychic act could not be the object of a scientific analysis: "Mind is a black box".

Until 1960's studies and interest about empathy were stop, but with computers spread and consequential arising of cognitivist revolution based on machine-state functionalism, psychologists rediscovered cognitive processes and their organization.

Inside this wide cultural field, empathic abilities studies exponentially spread with the "Theory of Mind" (ToM) a research field aimed at human ability of represent not only our mental state but another's too.

One of ToM's major interest object is the ability of metarepresentation, analyzed and studied according to Winner and Perner's "False beliefs" paradigm, also known as "Sally-Anne test" (Figure 1).

According to ToM it's necessary to firstly observe basic mental process, as false-belief task resolution, until to identify more complex ones, as be supportive with genocide survivors; this knowledge path leads to a differentiation between two empathic categories:

- Basic Empathy: the ability of directly recognize another one's emotional states.

- Renactive Empathy: the ability of find the source of another one's emotional states.

Over recent years it's been theorized a new model of empathy, known as "Dual Process" model in which are summarized two theories about its nature:

- Empathy arises from aware and control processes with which mental states can be inferred;

- Empathy is an automatic and unaware response to perceiving emotional contents from perceptional elements as facial expression or prosody.

So, according this model, Empathy can be defined as the

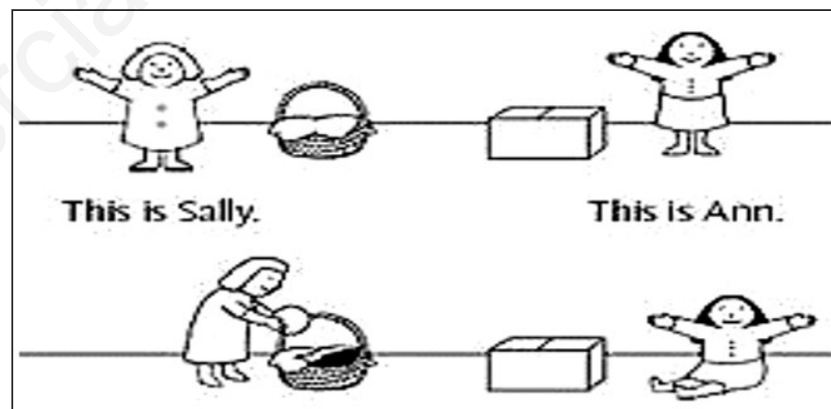

Sally has a ball. She puts it into her basket.

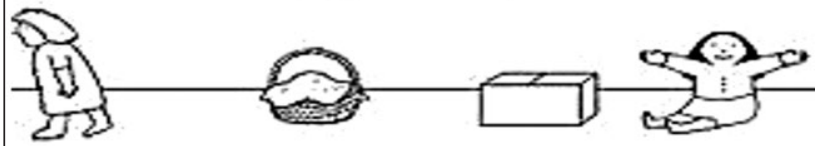

Sally goes out for a walk. Ann takes the ball out of the basket.

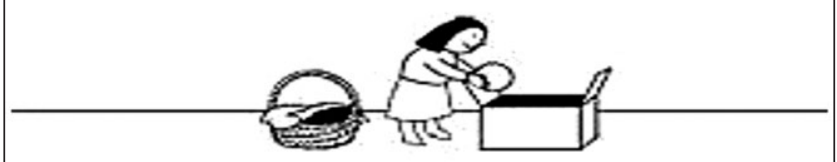

Ann then puts the ball in the box.

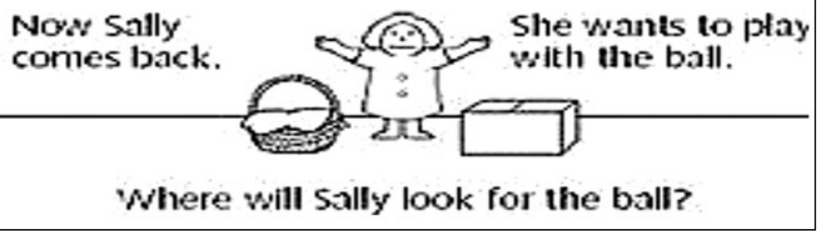

Figure 1. The "Sally-Anne test". For giving a correct answer, it is necessary to be on an advanced stage of mental development. 
process that results in the formation of a representation and understanding of the targets emotional state, which forms the basis of the empathizer's responses. This representation can occur without necessarily having direct emotional stimulation. The empathizer knows that the target is the source of the empathizer's emotional experience - there is a self-other differentiation. This emotional representation of the empathizer does not have to be isomorphic (i.e., the same) with that of the target, but can be; this is a departure from other theorists, especially those working in the neuroscience of empathy who view empathy as occurring only when the target's and empathizer's emotions are isomorphic.

\section{Empathy and morality}

Empathy requires a "going inside" in order to research any connection between empathic ability and acting moral ability its necessary to two essential statements:

- Empathy is a psychic act that requires a "going inside" in order to understand another one's inner reality;

- Every psychic act, as the mind itself, arisen from a material substratum: the brain.

So, how we can define a person a moral? Is it possible? Does it exist a universal and innate aptitude to virtuous behavior, or does exist innate virtues inside human nature?

In addition, when we define an act or a set of acts as "moral value": this definition should not be referred to a small group, but to all kind of human experiences.

So, here is that initial "quaestio" again, turn unobservable events into measurable objects by their tangible expressions; philosopher Patricia Churchland proposed a model of morality as an inner quadrimensional schema based on complex brain interconnections from which our inner-self arises, or "Synaptic Self" as defined by Joseph LeDoux:

- take care of another one, or attachment relationships;

- identify another one's psychological states, or empathy;

- problem-solving applied in a social contest;

- learning social abilities through: trial-and-error learning, modeling, classical or instrumental conditioning.

As it is well known, everything that modify behavior imply a changing in neural organization; so, being involved in a social relationship it's possible because of neuroplasticity that makes possible social and rational abilities learning.

In this regard an orbitofrontal cortex damage entails several consequences as cognitive impulsiveness or social intelligence defect named Acquired Sociopathy; those patients are characterized by lack of guilt, insensitivity and failure to understand consequence of their action in the social setting due to a severe empathic impairment.

So, if from a "simple" cortex trauma may result above mentioned consequences, then we may assume that the ability of distinguish between good and evil is partly inborn and influenced by our personal experiences in the social environment.

One of the most important researcher in that way is Lawrence Kohlberg, who theorized a rationalist moral development model based on his studies even on non-Western cultures, as Taiwanese, Mexican and Turkish ones.

\section{From Kohlberg to neuroethics}

Between 1950's and 1960's Kohlberg developed his theory based on Piaget's genetic epistemology. According the author it is possible to identify five stages of moral thinking development, which are culture-independent. Those stages, in turn, are grouped into three levels:

1. Pre-conventional level (up to age 9-10)

Cognitive structures are still primitive, so the individual evaluation of behavior is made only by personal consequences; this phase is characterized by two stages.

- Obedience and Punishment orientation;

- Self-interest orientation.

2. Conventional level (from 13 to 20 years of age)

In this case "conventional" means the ability of act not only for personal benefit, but personal behaviors are in accordance with own culture rules, expectations and convention. Individual's moral is oriented to interpersonal relationships and social values. We can identify two more stages:

- Interpersonal accord and conformity;

- Authority and social-order-maintaining orientation.

3. Post-conventional level (from 20 years of age on)

This level is characterized only by a single stage: social contract orientation. According Kohlberg at this level, there is such an abstract ability to reason that it is possible to focus on abstract ethic principles. There is no more an uncritical acceptance of law, which can be ignored in order to safe human rights.

For every single stage, cognitive impairment it is necessary but not sufficient, because are also needed empathic improvement and increased awareness of personal judgment, in order to exceed personal limits in that way.

By way of example, I am going to report results of a Kohlberg's questionnaire administration in its short form, the "Sociomoral Reflection Measure - Short Form" Italian version. Three middleschool classes took part to data collecting: 70 subjects aged between 11 and 14 years old. They answered to 11 open ended questions that firstly requiring to choose among three options (not important; important; very important) and then to justify giving a fuller answer. Participants had 30 minutes for questionnaire compilation; items are provided below:

1. Remember when you made a promise to a friend. How much is it important to keep a promise to a friend?

2. About promises: how much is it important to keep a promise to a person you barely know?

3. About make promises to children: how much is it important parents keep promises to their children?

4. Overall, how much is it important that people tell the truth?

5. Remember when you help your mother or father. How much is it important sons help their parents?

6. Let us assume that one of your friends needs help because he is risking life and you are the only one who can save him: how much is it important to save life to a friend without need to undermine your own safety?

7. About saving another one's life: how much is it important to save a stranger's life, without undermine your own safety?

8. How much is it important that someone lives even if he/she does not want to?

9. How much is it important to not grab another one's stuff?

10. How much is it important to respect the law?

11. How much is it important that judges send to prison who had not respect the law?

Figures 2 and 3 show frequency percentage of every moral developmental stages inside our samples.

Even if results show matching between sample's answers and Kohlberg's model, the latter is not free from limitations, especially by presuming a strong connection between moral behavior and knowledge of rules, because this connection could not explain why people deliberate choose to break the law, as a thief does. 
Even though those limitations, from Kohlberg's studies starts an increasing interest on physical, and so neural, roots of moral dilemmas resolution ability, that led to the birth of Neuroethics movement in 2002.

As it is written on the Neuroethics Italian Society Manifesto: "Adina Roskies proposed a partition between "Neurosciences' ethics" and "Ethic Neurosciences". This dichotomy underlines different and collateral topics on research:

- Neurosciences' ethic is about reflections on disputable applications of neurosciences;

- Ethic Neurosciences are oriented towards a meta-ethic reflection on neural bases of moral judgment.

Even if Neuroethics field is not totally defined yet, this discipline aims to study moral choices biological roots. First studies in that way were made in Princeton, where Jonathan Cohen did researches on moral dilemmas. According to Cohen, the manner in which a question is posed trigger emotional neural systems, and in so our answers depends on our past experiences and our personality features: the greater is personal involvement, the more our answers are similar to what it really happened in reality.

So, what are those areas involved in moral dilemmas resolution?

Northoff and colleagues' studies underline the medial-prefrontal cortex (MPC) and ventral striatum (VS) activation in moral judgment; indeed, frontal cortex is involved in several cognitive processes named Executive Functions, necessary for cognitive control of behavior consistently with external environment, internal stimuli and past personal experiences. MPC, in particular, is related to conflicting information elaboration and to behavior control; fMRI studies also underline its involvement, with VS too, into metacognition processes, especially inferring others' mental states.

\section{Clinical of morality}

Our brain is not a closed box organized in predetermined functions, that runs according to an "input-output" system with external environment, but it is continually involved in a relationship based on mutual exchange with its surroundings modifying its structures or modulating environment according to the needs. So, the question is, it is possible to use clinical training with patients with neural deficits that cause lacking in social and empathic skills in order to modify maladaptive behaviors? And, firstly, it is possible to educate people to prosociality?

\section{Childhood interventions}

In the public mind childhood is the "age of innocence" and people very rarely conceived that children can be affected by behavior and sociality disorders such serious as adulthood ones, and

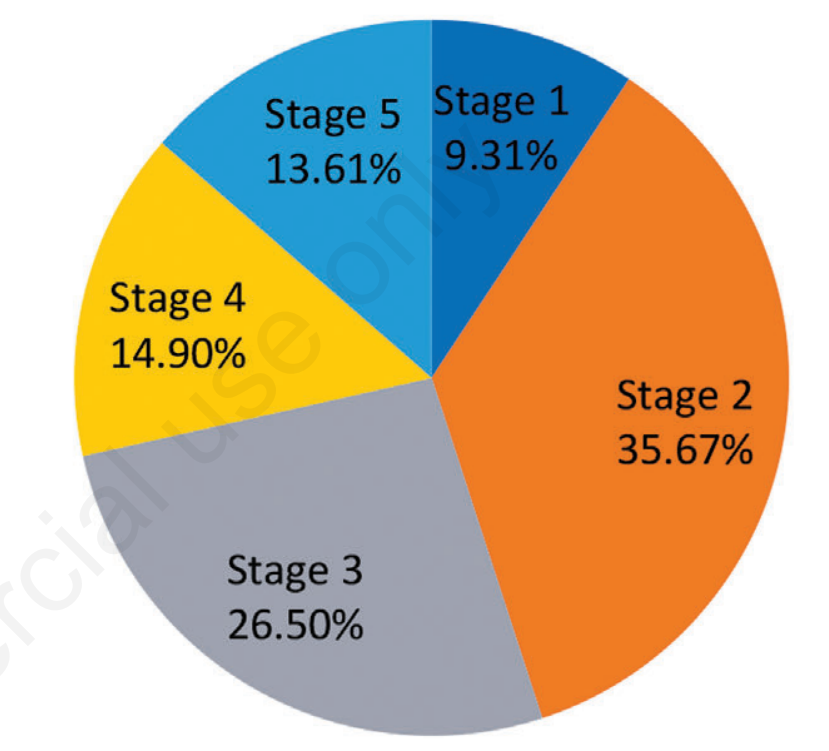

Figure 2. Percentage of stages frequencies in the sample.

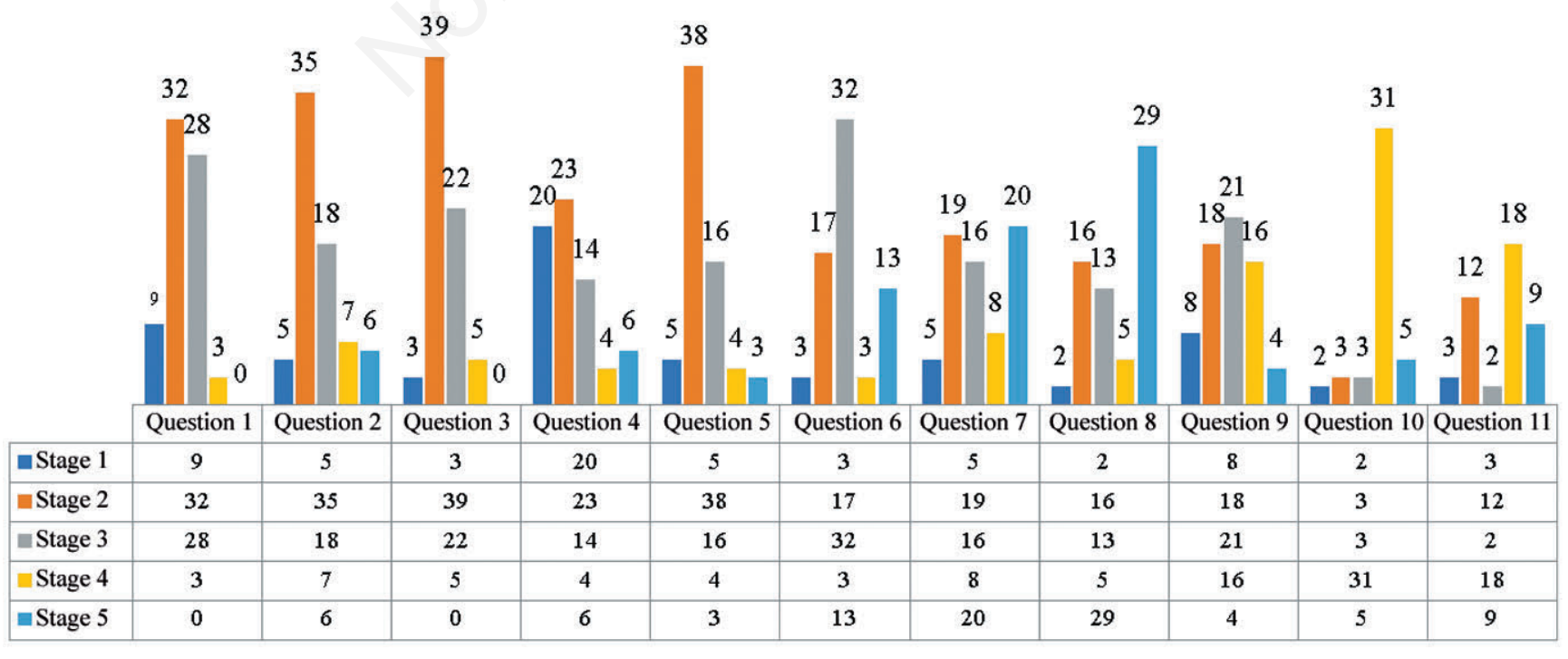

Figure 3. Frequencies of answers for every developmental stage. 
even if a child shows some of those symptoms, there's a generally tendencies to tag those behaviors as a simple developmental phase that will be overcome with the growth.

Instead, inside the Diagnostic and Statistics Manual of Mental Disorders (DSM, at its fifth edition, so DSM-5) can be found a diagnostic category named "Disruptive Behavior Disorder", characterized by failing in adapting to society behavioral standards. In particular patients show two specific areas deficits:

1. Emotional Control

2. Behavioral self-regulation.

These lacking lead to violating others' safety and contrary to social standards actions. Clinical researches founded three disorders belonging to abovementioned DSM category:

- Attention Deficit Hyperactivity Disorder (ADHD): first diagnosis carried out whit starting school, because is in this setting that a child starts to interact with others. Diagnosis can only occur only if symptoms showed up both at school and at home. Children affected by ADHD are very talkative, unable to play in a calm way and in class usually to stand up from the chair and walk down the room. Those behavioral modalities make very difficult to have good relation with classmates and peers.

- Oppositional Defiant Disorder (ODD): this disorder is an excellent example of a continuum line between normal and pathological behavior: children affected by ODD show standard childish conducts but in an exaggerate way that underline personal development as recurring low mood, tantrum exhibit and intentional incitements; one of essential symptoms is the false attribution of their wrong behaviors to others.

- Conduct Disorder (CD): this diagnostic class describes criminal acts during childhood and adolescence, and also may be Antisocial Personality Disorder (APD) prelude. Patient show cruelty do other people and animals and they use to threatening and manipulation for their personal benefit an interest. Symptoms are different between genders: males tend to be aggressive and females usually preferred non-violent acts, as lying and skipping school.

Lahey and Loeber assumed that exist a relation between $\mathrm{ADHD} / \mathrm{ODD} / \mathrm{CD}$ and it is also to predict future behaviors of those children during adulthood. According authors, only comorbidity between ADHD impacts on OD prognosis: children showing DC and ADHD symptoms together show disruptive behaviors, earlier outbreak and a more persistent disorders.

The "Journal of the American Academy of Child and Adolescent Psychiatry" suggest a common guide line to all clinical approaches for DC patients: "Requiring an interpersonal and psychoeducational therapy since DC tends to be a chronical disorder, it is necessary a long-term treatment with recurring clinical controls".

So, it is necessary a multiple setting clinical approach in which shall cooperate psychologists, psychotherapists, neuropsychiatrists and neurodevelopmental disorders therapists for which clinical goals must be: decrease of dysfunctional behaviors by detecting and modifying their roots, working on several life settings (family, social relationships, social environment, etc.), use of client-centered approach, preference for group-therapy.

Why a group setting is so important? The social reinforcement given by peer group is stronger that the adult one, so a peer group may promote social and interpersonal ability enhancement, according to Bandura's model of social learning. The gold-standard treatment are neuropsychological interventions based on ToM model and best outcomes come from homogenous groups according age and diagnosis. This therapeutic approach aims to:

- Self- management abilities acquisition through CBT techniques, as token-economy one, in order to teaching new coping abilities for individual and social stressors.
- Empathic ability enhancement, which is particularly deficient in DC patients.

- Problem solving ability enhancement in order to implement adaptive behaviors in everyday coping.

Very simple clinical tools are used in those settings, such as exercises in which one is asked to imagine being the protagonist of a frame situation presented by the therapist. For instance: two kids are fighting over a toy; How do you think would the child whose toy has been stolen be feeling? How could his facial expression be?).

Play group also appeared as an efficient use in therapy, in which children have to work together or focus their attention for win; for DC subjects those moments are very important in order to learn how to deal with anger and for promoting adaptive prosocial behaviors towards peers.

\section{Adulthood interventions}

As mentioned above Conduct Disorder can be considered as the prodromic stage of adulthood Antisocial Personality Disorder (APD) if not treated at an early stage.

This assertion seems simplistic if not framed within the wider notion of temperament; as all personality disorders, APD is a structural disease grounded on personality defined by Costa and McCrea as "unique and stable experience modality which is reflected in a predictable reactions patterns implemented in several situations". That modality is grounded on temperament, the biological personality base, that by persistent interacting with environment set up peculiar and personal experiences with self, others and the world.

APD is a diagnosis assigned to individuals who habitually and pervasively disregard or violate the rights and considerations of others without remorse. People with Antisocial Personality Disorder may be habitual criminals or engage in behavior which would be grounds for criminal arrest and prosecution, or they may engage in behaviors which skirt the edges of the law or manipulate and hurt others in noncriminal ways which are widely regarded as unethical, immoral, irresponsible, or in violation of social norms and expectations. Those with APD often possess an impaired moral conscience and make decisions driven purely by their own desires without considering the needs or negative effects of their actions on others. Impulsive and criminal behavior is common and also intolerance to frustration and absolute lack of guilty conscience. Frustration and punishment aren't sufficient condition for changing and there is a marked tendency to confirm their insensible view of the world and others.

Neuroimaging studied showed a substantial prefrontal grey and white matter reduction in subjects with APD, as compared to control group. A small volume of grey matter in prefrontal region is usually associated to a lower galvanic skin response during stressing social interactions, which is a physiological parameter linked with anxiety.

In view of this empirical supports, it could be theorized that pathognomonic features of APD, as lack of empathy and unselfish behavior may depend on specific neurological deficits in prosocial conduct involved cortical areas.

Pharmacological therapy could help; selective serotonin reuptake inhibitors (SSRI) seems to be able to reduce impulsiveness as also anticonvulsants does, which help with acting out too. But it is necessary to underline that drugs are not able to act on personality features and so therapy must require a long-term approach; interpersonal behaviors need a long time to be modified.

Even if every personality disorder needs peculiar treatment, there is some general principles. Since individuals with a personality disorder does not consider their behavior as problematic, it's 
necessary that patients constantly faced with negative consequences of their dysfunctional thought and acts; so, therapist must give patient a feedback of adverse consequences. Not infrequently it's necessary to define expressly the limitations of therapeutic relationships, for example that verbal aggressions or anger acting out are not allowed; those limitations help the patient to understand his actions consequences, support more adaptive conducts learning and undermine dysfunctional behaviors. Individual setting therapy is, usually, the gold-standard.

Is widely established that significant changes in social functioning and reduction of symptoms induce by psychotherapy are underlined by neural functional and structural changes and several evidences lead to a future use of neuroimaging for outcome evaluation.

\section{Autism and empathy}

Autism shares some common ground with the disorders analyzed until now: lack of empathic ability and treat others like inanimate objects. Leaving aside elements that differentiate this pathology from APD, as social interaction impairment or empathic inability, it is very rare to observe in autistic subjects antisocial and aggressive behaviors. There is a total absence of manipulatory tendencies, that is, instead, an essential feature of antisocial individuals.

This point leading to a consideration: people with autism diagnosis are truly indifferent to deep relationships with others, also due to a failure to empathize, but despite this, empathic impairment doesn't lead to socially harmful behaviors.

So, it is possible that empathy may not be the necessary and sufficient prerequisite for what we had defined moral above? Maybe neurobiological components of moral act identity could give us the final answer.

In 1997, a neuroimaging study identified neuroanatomical abnormalities in the weight of the brain in autistic subjects, especially of the cerebellum (involved in learning, motor control, attention and probably also in emotional functions) and the limbic system (involved in our behavioral and emotional responses, especially when it comes to behaviors we need for survival); it is also important underline again that those results had to be read carefully, because there is not deep knowledge of the same deficits in non-autistic subjects, and of the effect on those individuals.

It seems wise to me, therefore, to end those considerations emphasizing how human behavior and mind disclose all their complexity: at the very moment that we seem to found answer, this reveal how our current knowledge about it is wide and superficial at the same time.

\section{Conclusions}

At the end of this path, relationship between empathy and prosociality seems totally different to me and makes me aware of how incomplete are all the answers that I tried to find.

Saying that relationships exists or not it's a too dismissive and incomplete resolution. So, what's the point?

Firstly, according to "Mind-blindness-theory" of Simon BaronCohen, I considered essential a comparison between two dissimilar diagnostic classes as Autism and Antisocial Personality Disorder, from which arisen how empathy alone is not sufficient for acting in a moral, or prosocial, way.

Neither neuroscientific analysis had been able to identify the actual role of certain neural networks in prosocial behavior: even if neural differences between healthy subjects and those who showed behavior which deviate from social standard, there is not defined yet if those neural deficits are the cause or the consequence of pathological behaviors. We can only assume a correlation.

At the end, therefore, empathy is a neutral ability even though it is an essential component of interpersonal relationships. Without empathy another one appears to us as unreadable hieroglyphics, totally unavailable and indecipherable; psychology could not exist, as all humanities sciences. How could it be possible research universal and enduring human functioning principles without being sure that it is possible to match individual experiences?

So, empathy is an essential feature of human nature and even if it is not the only cause of moral acting, the answers about its origin may be found inside philosophy: free will. In this discussion this theme was not discussed, but it is undoubted that our possibility of choose is what makes our behaviors actually moral.

As reported by Ingmar Persson and Massimo Reichlin during Neuroethics Italian Society Congress of may 2015, empathy alone is not enough. According the researchers, last decades technologic innovation increased our power to damage our Planet through using mass destruction tools, as nuclear weapons, and causing nonreversible climatic and environmental changes; a moral enhancement race is necessary.

\section{References}

Agosta L. (2016). A rumor of empathy: rewriting empathy in the context of philosophy.

American Psychiatric Association (2013). Diagnostical and Statistical Manual of Mental Disorders, 5th Edition.

American Psychiatric Association (2000). Diagnostical and Statistical Manual of Mental Disorders, 4th Edition.

Baker K. (2016). Conduct Disorders in children and adolescents. Paediatrics Child Health 26: 534-539.

Basinger K. (1992). Socialmoral reflection questionnaire.

Camaioni L. (1995). La Teoria della Mente. Origini, sviluppo e patologia. Laterza Ed., Bari.

Churland P. (2012). Neurobiologia della morale. Raffaello Cortina Ed., Milano.

Davidov M., Vaish A., Knafo-Noam A., Hastings P.D. (2016). The motivational foundations of prosocial behavior from a developmental perspective-evolutionary roots and key psychological mechanisms: Introduction to the Special Section. Child Development Volume 87:1655-1667.

del Valle P., Kelley S.L., Seoanes J.E. (2001). The "oppositional defiant" and "conduct disorder" child: a brief review of etiology, assessment, and treatment. Behavioral Development 10:36-41.

Eisenberg N., Fabes R.A., Spinrad T. (2006). Prosocial development. In N. Eisenberg (Ed.), Handbook of child psychology: Social, emotional, and personality development. Vol. 3, 6th ed., pp. 646-718. Hoboken, NJ: Wiley.

Ferguson E. (2016). In: A. Wood, J. Johnson, The Wiley Handbook of Positive Clinical Psychology. Wiley \& Sons, Oxford, pp. 103-124.

Flook L., Goldberg S.B., Pinger L., Davidson R.J. (2015). Promoting prosocial behavior and self-regulatory skills in preschool children through a mindfulness-based kindness curriculum. Developmental Psychology 51:44-51.

Greene J.D., Nystrom L.E., Engell A.D., Darley J.M., Cohen J.D., (2004). The Neural Bases of Cognitive Conflict and Control in Moral Judgment. Neuron 44:389-400.

Gross J.T., Stern J.A., Brett B.E., Cassidy J. (2017). The multifaceted nature of prosocial behavior in children: Links with 
attachment theory and research. Social Development 1-18.

Kohut H. (2000). La Psicologia del Sé. Bollati Boringhieri Ed., Torino, pp. 83-84.

Kuhmerker L., Gielen U., Hayes R.L. (1995). L'eredità di Kohlberg. Intervento educativo e clinic. Giunti Ed., Firenze.

LeDoux J. (2002). Il Sé sinaptico. Raffaello Cortina Ed., Milano.

Northoff G. (2011). What is neuroethics? Empirical and Thoeretical neuroethics, moral behaviour and free will. If Press Ed., Città del Vaticano, pp. 81-92.
Paulus M. (2014). The emergence of prosocial behavior: why do infants and toddlers help, comfort, and share? Child Development Perspectives 8:77-81.

Titchener E. (1909). Experimental psychology of the thought processes, "Lectures on the experimental psychology of the thought-processes", Macmillan Ed, New York.

Wimmer H., Perner J. (1983). Beliefs about beliefs: Representation and constraining function of wrong beliefs in young children's understanding of deception. Cognition 13:103-128.

\section{Correspondence: Eleonora Pizzi}

E-mail: eleonora.pizzi@unier.it

Key words: Empathy; criminal; psychopathology; neurosciences; antisociality; moral; prosocial behavior.

Parole chiave: Empatia; criminale; psicopatologia; neuroscienze; antisocialità; morale; comportamento prosociale.

Palabras clave: Empatía; criminal; psicopatología; neurociencias; antisocialidad; moral; comportamiento prosocial.

Received for publication: 23 December 2017.

Revision received: 5 March 2018.

Accepted for publication: 19 April 2018.

This article is distributed under the terms of the Creative Commons Attribution Noncommercial License (by-nc 4.0) which permits any noncommercial use, distribution, and reproduction in any medium, provided the original author(s) and source are credited.

(C) Copyright E. Pizzi, 2018

Licensee PAGEPress, Italy

Rivista di Psicopatologia Forense, Medicina Legale, Criminologia

2018; $23: 22$

doi:10.4081/psyco.2018.22 